\title{
Controlling Size and Distribution for Nano-sized Polystyrene Spheres
}

\author{
Dong Shin Yun, ${ }^{\dagger,+}$ Hyeong-Seok Lee, ${ }^{\dagger, \$}$ Ho Gyeom Jang, ${ }^{\ddagger, *}$ and Jung Whan Yoo ${ }^{\dagger, *}$ \\ ${ }^{\dagger}$ Composite Materials Team, Korea Institute of Ceramic Engineering \& Technology, Seoul 153-801, Korea \\ EE-mail:jwyoo@kicet.re.kr \\ ${ }^{\ddagger}$ Department of Chemistry, Korea University, Seoul 136-701, Korea. ${ }^{*}$ E-mail: hgjang@korea.ac.kr \\ ${ }^{\S}$ Department of Chemical Engineering, Hanyang University, 12, Haendgang-dong, Seoul 133-791, Korea \\ Received November 9, 2009, Accepted March 24, 2010
}

\begin{abstract}
Highly monodisperse polystyrene (PS) nanospheres were fabricated by surfactant-free emulsion polymerization in water using styrene, 2,2'-azobis(2-methyl propionamidine) dihydrochloride (AIBA), and poly(vinyl pyrrolidone) (PVP). The size and distribution of the PS nanospheres were systematically investigated in terms of initiator concentration, stabilizer concentration, reaction temperature, reaction time, and reactant concentration. With increasing AIBA initiator concentration, PS particle sizes are raised proportionally, and can be controlled from 120 to $380 \mathrm{~nm}$. Particle sizes were reduced with increasing PVP concentration. This decrease occurs because a high PVP concentration leads to a large number of primary nuclei in the early stage of polymerization. When the reaction temperature increased, the sizes of the PS particles decrease slightly. The particles grew quickly during the initial reaction stage (1-3 h) and the growth rate became steady-state after $6 \mathrm{~h}$. The PS sizes approximately doubled when the reactant (styrene, PVP, azo-initiator) concentrations were increased by a factor of eight.
\end{abstract}

Key Words: Polystyrene, Nanospheres, Surfactant-free emulsion polymerization, Polymer

\section{Introduction}

Polymer spheres with nano- and micro-dimensions have received significant attention for their potential applications in display coatings, inks, dry toners, supports for biomedical and/or chromatographic applications. ${ }^{1-3}$ Among these applications, coating materials and spacers in PDP and LCD displays in particular need nano-sized polymer spheres with narrow distributions.

Since Matsumoto and Ochio first reported the preparation of monodisperse polystyrene (PS) microspheres by surfactantfree emulsion polymerization based on a styrene/potassium persulfate/water system in 1965 , the technique has attracted significant interest. ${ }^{4}$ Highly monodisperse PS spheres of narrow particle size distributions can be produced by one of the following three surfactant-free emulsion polymerization methods: (1) addition of an ionizable initiator, (2) use of surface active or amphoteric initiators. ${ }^{5-7}$

Although a few papers have reported synthesis of nano- or micro-size PS spheres with respect to various reaction conditions such as initiator types, styrene concentration, stabilizer types and concentration, ${ }^{8-11}$ still there is not enough understanding to control size and distribution for PS spheres by manipulating reaction parameters. When the relationship between these factors and size/distribution for the PS spheres is made clear, this technology can be commercially used in various fields.

In this paper, we systematically investigated synthesis of monodispersed PS spheres in different parameters such as initiator concentration, stabilizer concentration, reaction temperature, reaction time, and reactant concentration. The PS particle size and distribution of the formed PS nanospheres are explained.

\section{Experimental}

Materials. Styrene 98\%, (Aldrich co., USA), 2,2'-azobis (2-methyl propionamidine) dihydrochloride(AIBA, 97\%, Aldrich co., USA) were used without further purification. Poly (vinyl pyrrolidone) (PVP, $\mathrm{Mw}=55,000 \mathrm{~g} / \mathrm{mol}$, Aldrich co., USA) was used as a stabilizer. Deionized water with a resistivity higher than $18 \mathrm{M} \Omega \cdot \mathrm{cm}$ was used in all experiments as the reaction medium.

Synthesis of polystyrene (PS). Styrene polymerization was carried out in deionized water with AIBA as an initiator. PVP and AIBA were dissolved in deionized water in a $500 \mathrm{~mL}$ threeneck flask, and the styrene was added to the solution. The reaction temperature was gradually increased to $70{ }^{\circ} \mathrm{C}$ and kept at this temperature for $24 \mathrm{~h}$ before the mixture was finally allowed to cool to room temperature. As-synthesized PS particles were filtered and washed to remove the residual styrene and PVP with water and methanol. The sample was dried in a vacuum oven at $50^{\circ} \mathrm{C}$ for $12 \mathrm{~h}$. The PS spheres with various diameters were prepared similarly by changing reaction conditions such as initiator concentration, stabilizer concentration, reaction temperature, and reactant concentration. Morphology and size of PS particles were obtained from a Topcon, SM-300 scanning electron microscope (SEM).

\section{Results and Discussion}

Effect of initiator concentrations. Fig. 1 shows the effect of the various AIBA initiator concentrations on the PS size and shape in the surfactant-free emulsion polymerization of styrene. The as-synthesized PS particles were observed as sphereshaped with a narrow size distribution. With increasing AIBA 


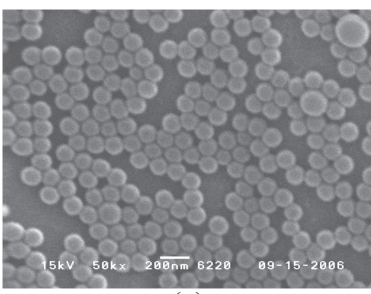

(a)

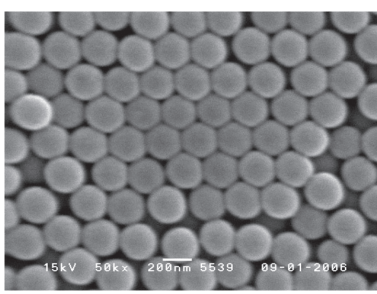

(c)

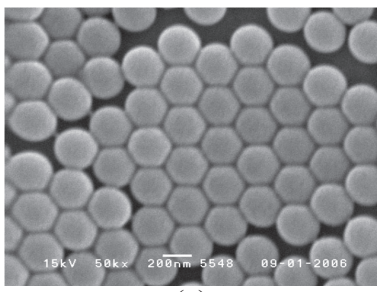

(e)

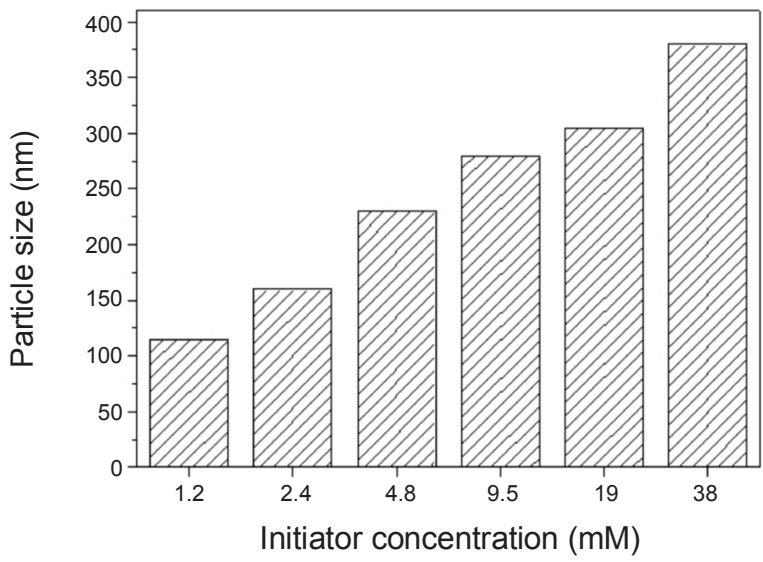

(B)

Figure 1. SEM images of PS synthesized at various AIBA initiator concentrations: (a) $1.2 \mathrm{mM}$, (b) $2.4 \mathrm{mM}$, (c) $4.8 \mathrm{mM}$, (d) $9.5 \mathrm{mM}$, (e) $19 \mathrm{mM}$, and (f) $38 \mathrm{mM}$. Styrene $0.96 \mathrm{M}$, PVP $300 \mu \mathrm{M}, \mathrm{H}_{2} \mathrm{O} 250 \mathrm{~mL}$, reaction time $24 \mathrm{~h}$, and reaction temperature $70^{\circ} \mathrm{C}$.

concentrations, the PS particle size increases proportionally, as shown in Fig. 1(B). The PS size can be controlled from 120 to $380 \mathrm{~nm}$ by changing the initiator concentration from 1.2 to $38 \mathrm{mM}$. It is known that the dependence of the final particle size on the initiator concentration is classified into two cases: ${ }^{11}$ the case in which the particle size decreases with increasing anionic or neutral initiator concentration, ${ }^{12,13}$ and the case in which the particle size shows the reverse trend with increasing cationic initiator concentration. ${ }^{14,15}$ The former mechanism is easily understandable, because a large number of nuclei are formed at the initial stage so that the final particle size becomes small for a given amount of monomer. On the other hand, the

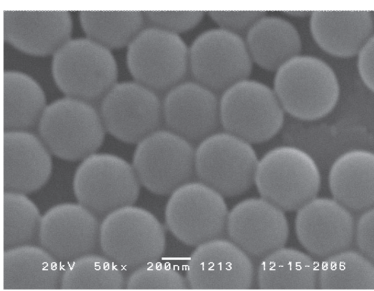

(a)

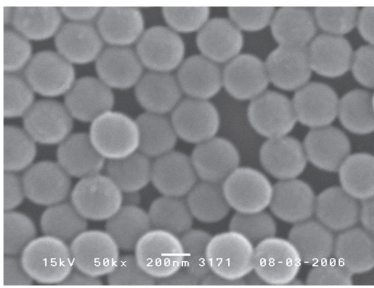

(c)

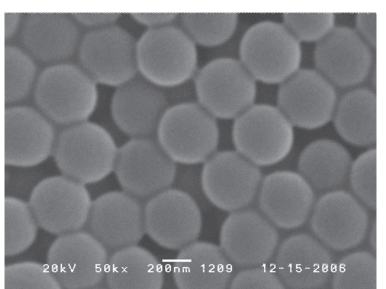

(b)

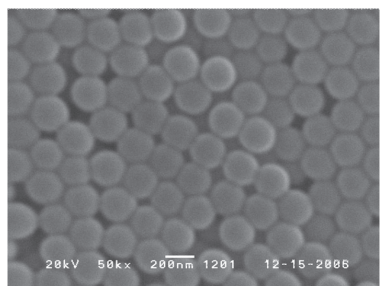

(d)
(A)

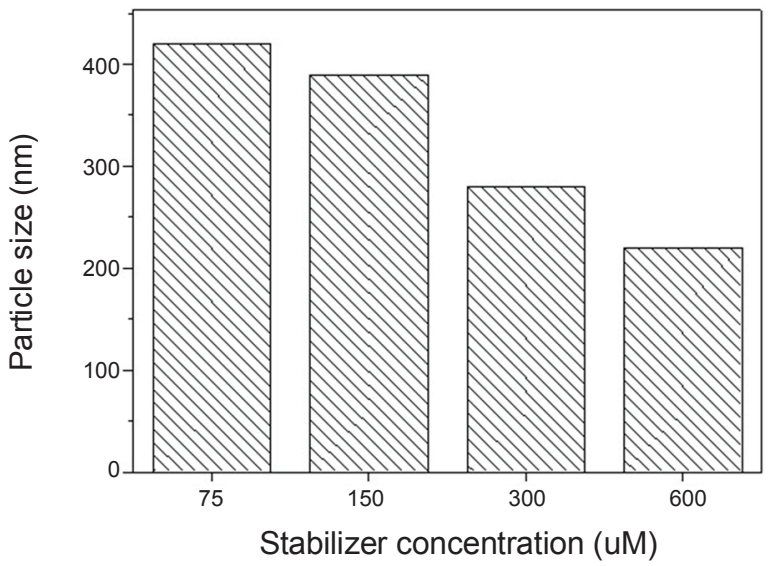

(B)

Figure 2. SEM images of PS prepared at various PVP stabilizer concentrations: (a) $75 \mu \mathrm{M}$, (b) $150 \mu \mathrm{M}$, (c) $300 \mu \mathrm{M}$, (d) $600 \mu \mathrm{M}$. Styrene $0.96 \mathrm{M}$, AIBA $9.5 \mathrm{mM}, \mathrm{H}_{2} \mathrm{O} 250 \mathrm{~mL}$, reaction time $24 \mathrm{~h}$, and reaction temperature $70{ }^{\circ} \mathrm{C}$.

mechanism for the latter case, which agrees with our observations, is less straightforward. However, this behavior can be explained in that large quantity of our cationic initiators, AIBA result in great numbers of styrene free radicals, which accelerate growth of existing oligomers, nuclei, and nanoparticles. Therefore, higher initiator concentrations resulted in larger PS particles compared to those prepared by lower concentrations of initiator.

Effect of stabilizer concentrations. The influence of PVP stabilizer concentration on the PS size was studied under same reaction conditions (Fig. 2). The as-prepared PS particles had neither coagulation, nor secondary particles. The PS particles were again entirely sphere-shaped, and the overall size decreased with increasing stabilizer concentration. For example, a $50 \%$ size decrease was observed (420 nm to $210 \mathrm{~nm}$ ) when the stabilizer concentration was increased from $75 \mathrm{uM}$ to 600 $\mathrm{uM}$. Since the surface of the PS spheres is negatively charged due to the presence of sulfate groups, interaction is likely to occur between these charged groups and the positive side of the dipoles occurring in the PVP chains. ${ }^{16}$ Therefore, the PVP 


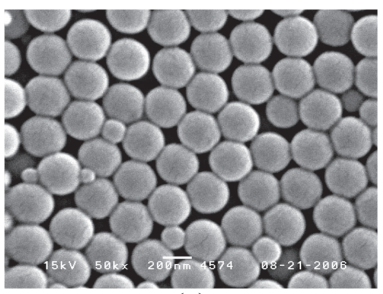

(a)

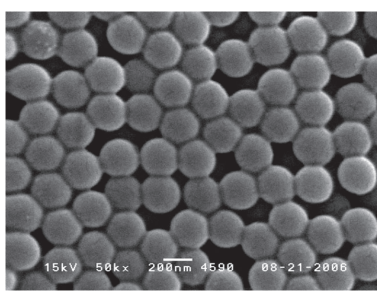

(c)

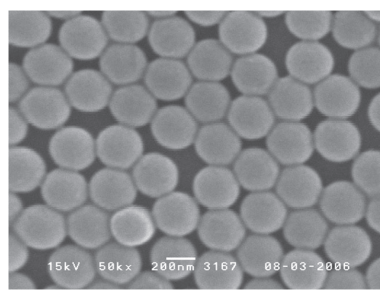

(b)

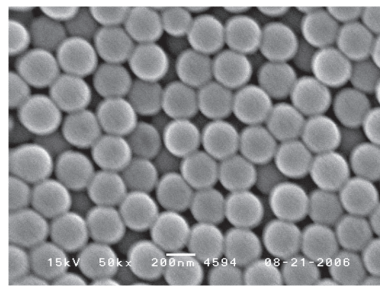

(d)
(A)

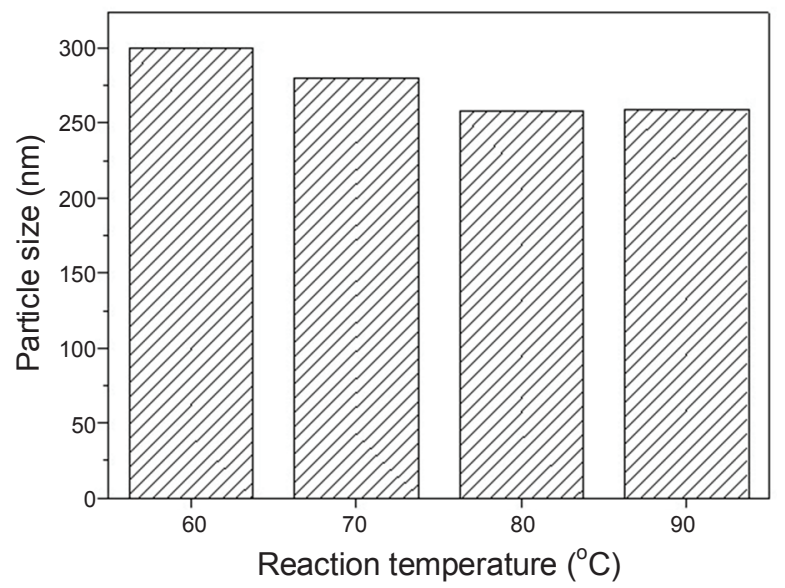

(B)

Figure 3. SEM images of PS synthesized at various reaction temperatures: (a) $60^{\circ} \mathrm{C}$, (b) $70^{\circ} \mathrm{C}$, (c) $80^{\circ} \mathrm{C}$, and (d) $90^{\circ} \mathrm{C}$. Styrene $0.96 \mathrm{M}$, PVP $300 \mu \mathrm{M}$, AIBA $9.5 \mathrm{mM}, \mathrm{H}_{2} \mathrm{O} 250 \mathrm{~mL}$, and reaction time $24 \mathrm{~h}$.

stabilizer provides colloidal stability to the newly formed insoluble polymer spheres by adsorption of PVP chains on their surfaces via attractive ionic-dipole interactions, preventing further coagulation. ${ }^{16}$ Such interactions are more than enough to bind PVP. A higher concentration of PVP would lead to a large number of primary nuclei in the early stage of polymerization, ${ }^{8}$ which results in larger amounts of PVP giving smaller PS spheres.

Effect of reaction temperatures. The effects of reaction temperatures on the PS particle size and size distribution are illustrated in Fig. 3. When the reaction temperature increased, the sizes of the PS particles decreased proportionally. As the temperature varied from 60 to $90{ }^{\circ} \mathrm{C}$, the particle sizes changed from 300 to $250 \mathrm{~nm}$. The particles sizes might be affected by the degree of concentration of primary free radicals produced by the AIBA initiator, which is a function of the reaction temperature. At higher temperatures, many free radicals were produced in a short time compared to lower temperatures, resulting in more primary nuclei, resulting in smaller PS spheres.

Effect of reaction times. Fig. 4 indicates the growth of the

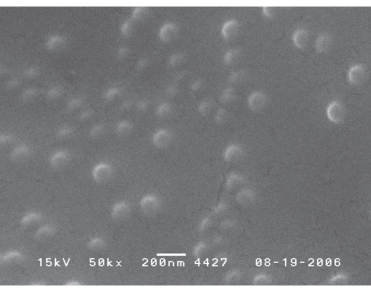

(a)

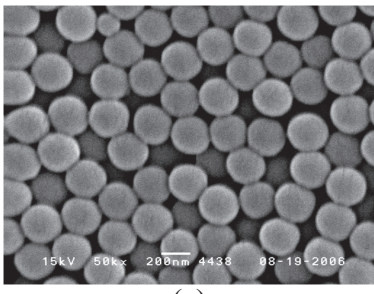

(c)

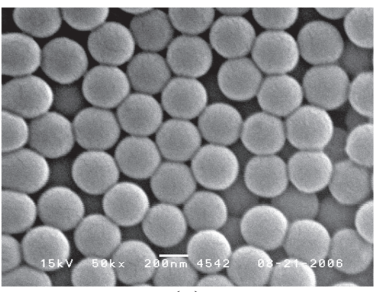

(e)

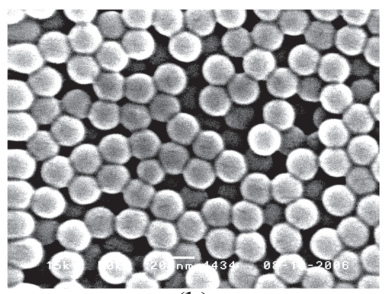

(b)

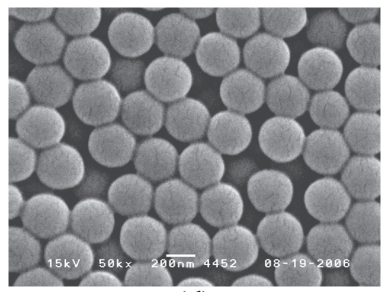

(d)

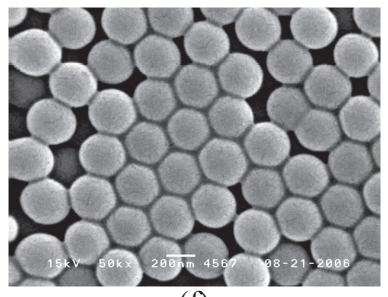

(f)

(A)

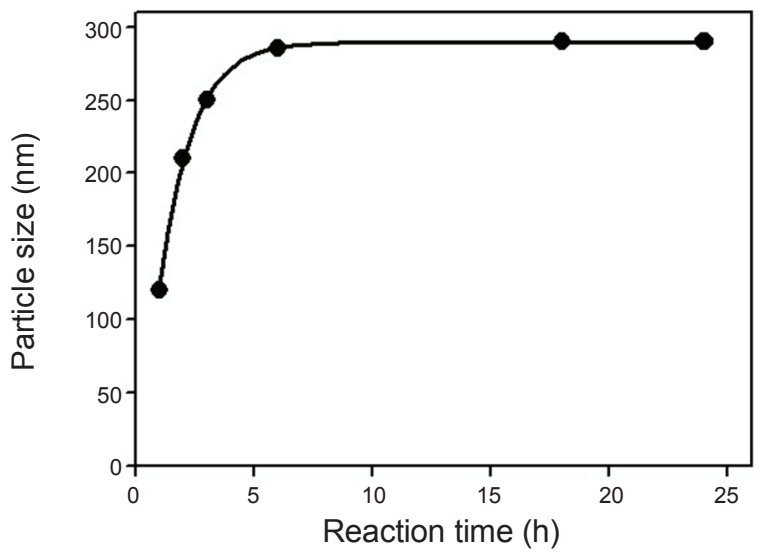

(B)

Figure 4. SEM images of PS synthesized at various reaction times: (a) $1 \mathrm{~h}$, (b) $2 \mathrm{~h}$, (c) $3 \mathrm{~h}$, (d) $6 \mathrm{~h}$, (e) $18 \mathrm{~h}$ and (f) $24 \mathrm{~h}$. Styrene $0.96 \mathrm{M}$, PVP $300 \mu \mathrm{M}$, AIBA $9.5 \mathrm{mM}, \mathrm{H}_{2} \mathrm{O} 250 \mathrm{~mL}$, and reaction temperature $70{ }^{\circ} \mathrm{C}$.

PS particles according to reaction time. At a reaction time of $1 \mathrm{~h}$, the particles were mainly round in shape, but unclear shapes and broad size distributions were also observed. The PS particles show a very clear shape with narrow size distribution after reaction for $2 \mathrm{~h}$. The particles grew quickly during the early stages of reaction ( $1-3 \mathrm{~h}$ ), while the growth rate became steadystate after $6 \mathrm{~h}$. These results demonstrate that reaction time is important in the control the PS size. J. Lee et al. synthesized highly monodispersed PS spheres by using styrene, initiator, PVP stabilizer, and methanol solvent at $60{ }^{\circ} \mathrm{C} .{ }^{8}$ They have observed that the PS spheres sizes were continuously increased with the polymerization time of $6 \mathrm{~h}$, and then become constant 
(a)

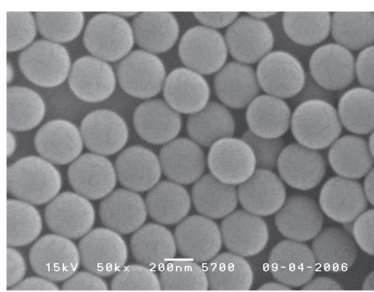

(c)

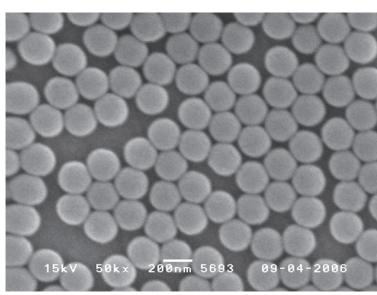

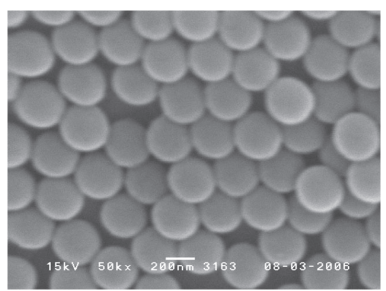

(b)

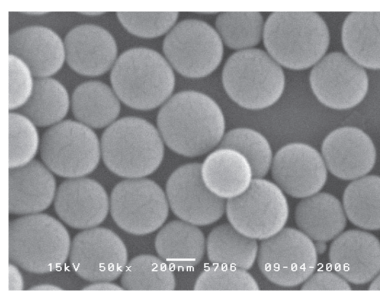

(d)
(A)

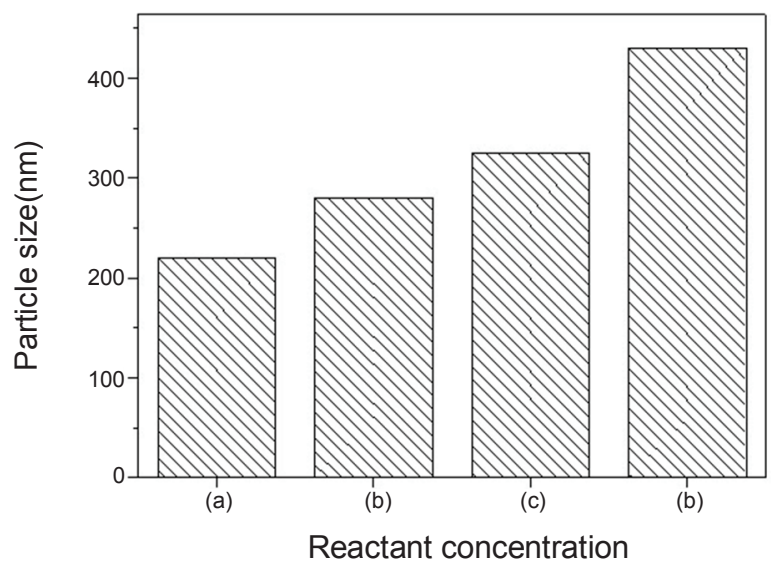

(B)

Figure 5. SEM images of PS at various reactant concentrations: (a) Styrene 12.5 g, PVP $1.87 \mathrm{~g}$, and Azo-initiator $0.33 \mathrm{~g}$, (b) Styrene $25 \mathrm{~g}$, PVP $3.75 \mathrm{~g}$, and Azo-initiator $0.65 \mathrm{~g}$, (c) Styrene $50 \mathrm{~g}$, PVP $7.5 \mathrm{~g}$, and Azo-initiator $1.3 \mathrm{~g}$ and (d) Styrene $100 \mathrm{~g}$, PVP $15 \mathrm{~g}$, Azo-initiator $2.6 \mathrm{~g}$. $\mathrm{H}_{2} \mathrm{O} 250 \mathrm{~g}$, reaction time $24 \mathrm{~h}$, and reaction temperature $70{ }^{\circ} \mathrm{C}$.

after $12 \mathrm{~h}$. These trends are similar to ours, but with different overall times for the initial and steady state reaction stages, presumably due to the different solvent.

Effect of reactant concentrations. In industrial applications, reactant concentration within the solvent is very important, as this is interrelated to economic feasibility and environmental contamination. Fig. 5 exhibits the relationships between reactant (styrene, PVP, azo-initiator) concentrations and PS sizes and shapes. The shapes of the PS particles were shown to be spherical for all reactant concentrations studied. PS particle sizes increased from $220 \mathrm{~nm}$ to $420 \mathrm{~nm}$ when the reactants concentrations were increased by a factor of eight. The size increase is almost constant (Fig. 5 a-c); however, at high concentration, a bimodal size distribution was observed. By increasing the concentration the solvency of the continuous phase increases, so that the oligomers grow to a longer chain length before precipitation, the adsorption rate of the stabilizer on the particles surface decreases, and the swelling of the particles by the styrene increases. In addition, we believe that increasing the styrene concentration results in a lower particle surface polarity, which increases not only the swelling of the PS particles by styrene, but also the agglomeration of PS nuclei and the seed polymerization of styrene on the particle surface.

\section{Conclusions}

PS nanospheres were produced by surfactant-free emulsion polymerization in water using styrene, 2,2'-azobis(2-methyl propionamidine) dihydrochloride (AIBA), and poly(vinyl pyrrolidone) (PVP). The size and distribution of the PS nanospheres were systematically investigated in terms of initiator concentration, stabilizer concentration, reaction temperature, reaction time, and reactant concentration. The results are summarized as follows.

1. With increasing AIBA initiator concentrations, the PS particle size increased significantly.

2. The PS particle size decreased with increasing PVP stabilizer concentration.

3. PS particle size decreased slightly with increasing reaction temperature.

4. Particles grew quickly during the initial stage of the reaction $(1-3 \mathrm{~h})$ and reached steady-state after $6 \mathrm{~h}$.

5. The PS particle sizes approximately doubled with an 8-fold increase in the reactant (styrene, PVP, azo-initiator) concentration.

Based on this work, the size and distribution for the PS nanospheres can be controlled using various reaction factors.

Acknowledgments. This work was supported by Energy· Resources Technology R\&D program under the Ministry of Knowledge Economy and the Industrial Technology Development program of the Korea Institute for Advancement of Technology (KIAT).

\section{References}

1. Fudouz, H.; Xia, Y. Adv. Mater. 2003, 15, 892.

2. Ugelstad, J.; Stenstad, P.; Kilaas, L.; Prestvik, W. S.; Rian, A.; Nustad, K.; Herje, R.; Berge, A. Macromol. Symp. 1996, 101, 491.

3. Covolan, V. L.; Mei, L. H. I.; Rossi, C. L. Polym. Adv. Technol. 1997, 8, 44.

4. Matsumoto, T.; Ochio, A. Kobunshi Kagaku 1965, 22, 481.

5. Orihara, S.; Konno, M. J. Colloid Interface Sci. 2000, 230, 210.

6. Aslamazova, T. R.; Tauer, K. Colloids Surf. A 2007, 300, 260.

7. Yamada, Y.; Sakamoto, T.; Gu, S.; Konno, M. J. Colloid Interface Sci. 2005, 281, 49.

8. Lee, J.; Ha, J. U.; Choe, S.; Lee, C. Shim, S. E. J. Colloid Interface Sci. 2006, 298, 663.

9. Du, X.; He, J. J. Appl. Polym. Sci. 2008, 108, 1755.

10. Bamnolker, H.; Margel, S. J. Polym. Sci. Polym. Chem. Ed. 1996, 34, 1857.

11. Yamamoto, T.; Nakayama, M.; Kanda, Y.; Higashitani, K. J. Colloid Interface Sci. 2006, 297, 112.

12. Wang, D. P.; Sudol, E. D.; Dimonie, V. L.; El-Aasser, M. S. J. Appl. Polym. Sci. 2002, 84, 2692.

13. Xu, J.; Li, P.; Wu, C. J. Polym. Sci. Part. A. Polym. Chem. 1999, 37, 2069.

14. Chern, C.-S.; Lin, C.-H. Polymer 2000, 41, 4473.

15. Yamamoto, T.; Iuoue, M.; Kanda, Y.; Higashitani, K. Chem. Lett. 2004, 33, 1440.

16. Paine, A. J. J. Colloid Interface Sci. 1990, 138, 157. 